\title{
PRIMITIVE REFLEXES AND COGNITIVE FUNCTION
}

\author{
Alfredo Damasceno', Adriane M. Delicio', Daniel F.C. Mazo', \\ João F.D. Zullo', Patricia Scherer', Ronny T.Y. $\mathrm{Ng}^{1}$, Benito P. Damasceno ${ }^{2}$
}

\begin{abstract}
Background: Data on the prevalence of primitive reflexes (PR) in adulthood, their pathological significance and relationship to age and cognition are controversial. Objective: To study therelationship between PR and cognition in 30 patients with probable Alzheimer's disease (AD) and 154 control subjects. Method: Diagnosis of probable AD was based on DSM-IV, NINCDS-ADRDA, and CAMDEX criteria. Primitive reflexes were quantified from zero (absent) to 1 (mild) or 2 (markedly present). The Cognitive Abilities Screening Instrument - Short Form (CASI-S) was used to evaluate registration, temporal orientation, verbal fluency and recall. A drawing test was added. Results: Most frequent PR among demented and controls were suck ( $77 \%$ and $62 \%$, respectively) and snout $(60 \%$ and $27 \%)$, followed by glabellar (30\% and $19 \%)$, paratonia ( $37 \%$ and $5 \%$ ), and palmomental $(23 \%$ and $5 \%)$. None of controls had more than three PR. Frequency of PR tended to increase with age and cognitive deterioration. Grasp and Babinski responses were found only in dementia patients. Primitive reflexes were not correlated with each other, except snout with suck, and snout with glabellar reflex. Conclusion: The finding of grasp and Babinski sign, or the presence of more than three primitive signs, particularly the combination of paratonia, snout, suck, and palmomental reflexes strongly suggests brain dysfunction, especially when these signs are marked and accompanied by deficits in orientation, recall, verbal fluency, and constructional praxis.
\end{abstract}

KEY WORDS: primitive reflexes, aging, dementia, Alzheimer's disease, cognitive tests.

\begin{abstract}
Reflexos primitivos e função cognitiva
RESUMO - Contexto: A prevalência e significado patológico dos reflexos primitivos (RP) no adulto, bem como sua relação com a idade e a cognição, são questões controversas. Objetivo: Estudar a relação entre RP e cognição em 30 pacientes com doença de Alzheimer (DA) e 154 sujeitos controles nomais. Método: $O$ diagnóstico de DA baseou-se nos critérios DSM-IV, NINCDS-ADRDA e CAMDEX. Os RP foram quantificados de 0 (ausente) a 1 (leve) ou 2 (acentuado). CASI-S (Cognitive Abilities Screening Instrument -Short Form) foi usado para avaliar o registro, orientação temporal, fluência verbal e evocação. Um teste de cópia de pentágonos foi acrescentado. Resultados: Os RP mais frequentes nos pacientes e controles foram o de sucção (77\% e $62 \%$, respectivamente) e "snout" (60\% e $27 \%)$, seguidos do glabelar ( $30 \%$ e $19 \%)$, paratonia $(37 \%$ e $5 \%)$ e palmomentoniano ( $23 \%$ e $5 \%)$. Nenhum sujeito controle teve mais que três RP. A frequência dos RP tendeu a aumentar com a idade e a deterioração cognitiva. $O$ reflexo de preensão e o sinal de Babinski foram encontrados apenas nos pacientes com DA. Os RP não se correlacionaram uns com os outros, exceto o reflexo "snout" com o de sucção e com o glabelar. Conclusão: O achado de reflexo de preensão e sinal de Babinski, ou a presença de mais de três sinais primitivos, particularmente a combinação de paratonia e reflexos "snout", sucção e palmomentoniano, são sugestivos de disfunção cerebral, especialmente quando esses sinais são acentuados e acompanhados de déficits de orientação, evocação, fluência verbal e praxia construcional.
\end{abstract}

PALAVRAS-CHAVE: reflexos primitivos, envelhecimento, demência, doença de Alzheimer, testes cognitivos.

Primitive reflexes (PR) are adaptive reactions occuming in the neonatal life and disappearing as the brain matures. Their reappearance in adulthood usually indicates cortico-subcortical neuronal loss, associated with normal aging or dementia ${ }^{1-8}$. Most of these reflexes are found in normal individuals, even in young adults: palmomental in $6 \%$ to $27 \%$ of subjects aged 20 to 50 years, and $28 \%$ to $60 \%$ of those above 60 years; snouting in $13 \%$ of subjects between 40 and 57 years, and $22 \%$ to $33 \%$ of those above 60 years age ${ }^{9}$; and even suck reflex, which for some authors ${ }^{10}$ "invariably indicates frontal lobe disease", has been found in $6 \%$ or more of normal subjects aged 73 to 93 years ${ }^{2}$.

\footnotetext{
Department of Neurology, Medical School, State University of Campinas, Campinas SP Brazil, (FCM/UNICAMP): 'Medical Student, ${ }^{2}$ Associate Professor. This research was supported by FAPESP (Fundação de Amparo à Pesquisa do Estado de São Paulo) grants 99/05287-7, 99/05288-3, 99/05289-0, 99/05290-8, and 99/05291-4.
}

Received 1 October 2004, received in final form 5 January 2005. Accepted 22 March 2005.

Dr. Benito P. Damasceno - Department of Neurology / FCMIUNICAMP / Box 6111 - 13083-970 Campinas SP - Brasil. E-mail: damascen@ unicamp.br 
Thus, the prevalence of these reflexes is largely varied, and there is disagreement on their pathological significance, and even on their increasing frequency with aging. Only grasp reflex and extensor plantar response (Babinski sign) are well established as indicators of disease in the central nervous system. These controversies may be explained by conceptual and methodological differences between authors. As regards the interpretation of motor response, for example, some may consider as positive suck reflex only the contraction of lip muscles, while others require additional lingual and pharyngeal sucking movements. There can also be differences concerning variables which can influence prevalence of PR, such as heterogeneity of diseases on the patient groups studied, lack of stantardized quantified protocols, stimulation strenght ${ }^{11}$ and subject's emotional state, which can influence the magnitude and persistence of responses.

The relationship between PR and cognitive deficits has also been controversial. Some authors ${ }^{2,3}$ reg a rd these reflexes as predictive of diffuse cerebral dysfunction, since these signs were significantly correlated to cognitive deficits determined by the Halstead-Reitan Neuropsychological Battery in a group of 76 individuals aged 20 to 80 years. On the other hand, other authors ${ }^{12}$ found no correlation between snout, glabellar, and grasp reflexes and the presence of cerebral atrophy by CT scan or the results of psychometric tests (Wechsler Memory Scale) in a sample of 52 patients with Alzheimer's disease and 48 normal controls.

Our aim was to study the relationship between PR and cognitive function in aging individuals with or without dementia, and to verify what items of ne urdogical exam and cognitive testing are more $p$ redictive of brain dysfunction. For this we chose The Cognitive Abilities Screening Instrument Short Form (CASI-S) ${ }^{13}$ as psychometric test, since it has the most predictive items found in other test batteries ${ }^{14,15}$, with graded scoring of responses, besides it being a short, practical test, resistant to c ross-cultural influences (suitable for illiterate subjects), and sensitive for detecting dementia ${ }^{13}$.

\section{METHOD}

Subjects - This study included subjects aged 40 to 95 years, even illiterate ones, comprising patients with Alzheimer's disease attended at our university hospital, and normal controls recruited from the community, insofar as they could be matched with the patients for age (within 5 years) and education (within 2 years), were motivated to participate in the study and had auditory and visual acuity good enough to perform the tests. Exclusion criteria for normal controls were history or evidence of neurological or psychiatric disease, head trauma with loss of consciousness exceeding $30 \mathrm{~min}$, alcoholism or occupational exposition to neurotoxic substances, and current use of medication likely to affect cognitive function. All subjects gave their informed consent to participate, in accordance with the rules of our Medical School Ethics Committee.

Procedures - All subjects underwent medical history and neurological examination with standardized evaluation of PR, classified in 0 (absent), 1 (slightly present) or 2 (markedly present). Testing took place at morn ing times in a quiet room of the hospital (Neuropsychology Unit). The techniques (which follow) were based on those used by Paulson and Gottlieb ${ }^{1}$ and Koller et al. ${ }^{12}$.

Palmomental. This reflex was present if any n o t i c eable contraction of the mentalis muscle could be elicited by a vigorous stroke of the thumbnail along the ipsilateral thenar eminence. It got score 1 if the response was weak, vanishing in 10 consecutive stimulations; or score 2, if markedly present and persistent.

Snout. As described by Koller et al. ${ }^{12}$, the examiner tapped slightly with his index finger midline on the subject's upper lip, which could give only a weak puckering (score 1) or prot rusion of the lips, with elevation of the lower one (score 2).

Suck. This was elicited by firmly placing the tip of the patient's index finger between his closed lips. The response could be incomplete, with only weak contraction of orbicularis oris muscle (score 1) or full, with sucking movements of the tongue and pharynx (score 2)

Glabellar. The subject was directed to fix the examiner's left index finger positioned $30^{\circ}$ down, at a distance of $50 \mathrm{~cm}$, while the examiner approached his right index finger from above the patient's forehead (outside the visual field to eliminate visual threat as a stimulus), and tapped the region between the eyebrows 10 times (2 times per second), asking the subject not to blink. Blink responses that disappeared (habituated) before the tenth tap scored 0 , while continuous synchronous blinking after nine taps scored 2 (if with complete closing of eyelids) or 1 (if closing was incomplete).

Grasp. The subject sat with hands in lap, palms upw a rd, and eyes closed, counting backwards from 20 (to distract his attention). Then the examiner's second and third fingers stroked lightly on de subjects palm from the back of the hand. If the subject grasped the examiner's fingers, he or she was asked not to. The procedure was repeated; if the patient continued to grasp, the reflex was pre sent, and got score 1 if only weak finger flexion and thumb adduction in an attempt to grasp, or score 2 if firm closure around the examiner's fingers.

Paratonia. The examiner tested the subject's resting muscle tone in the arms and legs by passive, irregular 
extension and flexion. Intermittent opposition to the examiner's movements despite instructions to relax, resulting in a catching or resistive sensation, was considered as paratonia (Gegenhalten), which could be differentiated from the full range, regular Parkinsonian rigidity and the clasp knife spasticity.

Cognitive evaluation with the validated Brazilian version of CASI-S ${ }^{16,17}$, comprising following subtests: reg istration (repeating three words: shirt, brown, honesty; score 0 to 3); temporal orientation with graded scoring according to the closeness of the response to the correct answer (to year: $0-4$; to month and date: $0-5$; to week-day: 0-1; and to the time of day, allowing 59 minutes error: 0-1); verbal fluency (category: four-legged animals, scoring the number of correct answers in 30 seconds, up to 10); and recall (remembering three words): spontaneous recall of each correct word got score 3; recall after category cueing (e.g., "something to wear"), score 2; recall after provided three choices (e.g., "shoes, shirt, socks"), score 1; and if still incorrect answer, score 0 . CASI-S maximum score is 33 points. A test of constructional praxis was added (copy of two intersecting pentagons or, for illiterate subjects, reproduction of two pentagons bound by one of their sides using matches; score 1 if correctly copied).

Diagnosis of dementia was based on DSM-IV criteria $^{18}$, as well as on NINCDS-ADRDA ${ }^{19}$ for Alzheimer's disease. CAMDEX ${ }^{20}$, which contains a battery of cognitive testes (CAMCOG), was used to grade dementia (in mild, moderate and severe) and to differentiate it from depression. Computed tomography (CT), magnetic resonance imaging (MRI), cerebral blood flow imaging (SPECT tomography using technetium-99m-HMPAO), electro encephalography, cere brospinal fluid analysis, and relevant laboratory blood tests were done to discard other causes of dementia. Evaluation of control subjects consisted only of medical history, physical-neurological examination, and cognitive testing with CASI-S.

Data were entered into Statistica. The $\beta^{2}$ statistic, Student $t$, ANOVA, Mann-Whitney $U$ test, Pearson correlation coefficient, and regression analysis were applied where appropriate. Significance level was 5\% (two-tailed).

\section{RESULTS}

We studied 30 patients with Alzheimer's disease ( 16 mild, 6 moderate, and 8 severe) and 154 cont rols (see Tables 1 and 2). Both groups had similar mean age and educational level (Student $t$ test). Seven controls and one patient with dementia were illiterate. Proportion of women was higher in the control group, but not statistically significant $\left(\beta^{2}=2.76, p=0.096\right)$.

On CT and MRI, 22 (73.5\%) dementia patients had diffuse cortico-subcortical atrophy (with parietal-temporal predominance in three cases), and
Table 1. Demographics.

\begin{tabular}{|c|c|c|c|}
\hline & $\begin{array}{l}\text { Controls } \\
(\mathrm{N}=154)\end{array}$ & $\begin{array}{l}\text { Alzheimer's } \\
\text { disease } \\
(\mathrm{N}=30)\end{array}$ & $p$ \\
\hline Men/women & $82 / 72$ & $11 / 19$ & 0.096 \\
\hline Age (years) & $68.5 \pm 6.8$ & $70.9 \pm 9.1$ & 0.14 \\
\hline Education (years) & $5.3 \pm 4.5$ & $6.5 \pm 4.4$ & 0.19 \\
\hline
\end{tabular}

$8(26.5 \%)$ were normal. SPECT done in 26 dementia patients showed bilateral or unilateral cortical hypoperfusion in posterior regions in most of them. SPECT data were classified according to Nitrini ${ }^{21}$ (modified from Holman et al.) 22 into the following perfusion patterns: $\mathrm{A}$ : normal; $\mathrm{B}$ : bilateral posterior temporal and/or parietal cortex defects; $\mathrm{C}$ : bilateral posterior temporal and/or parietal cortex defects with or without additional defects; D: unilateral posterior temporal and/or parietal cortex defects with or without additional defects; $\mathrm{E}$ : hipoperfusion predominantly frontal; $F$ : other re Iatively large $(>1 \mathrm{~cm})$ defects; $\mathrm{G}$ : multiple small cortical defects; and $\mathrm{H}$ : diffuse cortical hipoperfusion. One way ANOVA revealed diffe rences [though $\mathrm{F}$ $(4,21)=2.83, p=0.0504]$ between these perfusion patterns as regards the total scores of $P R$, on account of the highest PR scores of pattern $\mathrm{H}$ subgroup as compared to pattern $\mathrm{B}(t=2.3745, \mathrm{p}=$ $0.037)$ and pattern $\mathrm{D}(t=2.7005, \mathrm{p}=0.029)$.

On cognitive subtests, dementia patients had lower scores in registration $(p=0.003)$, temporal orientation $(p=0.0001)$, verbal fluency $(p=0.0001)$, recall $(p=0.0001)$, and constructional praxis $(p=$ 0.0002 ), as determined by Mann-Whitney $U$ test.

Most frequent PR in both groups (of demented and controls) were suck ( $77 \%$ and $62 \%$, respectively) and snout ( $60 \%$ and $27 \%)$, followed by glabellar (30\% and $19 \%)$, paratonia (37\% and $5 \%$ ) and palmomental (23\% and $5 \%$ ). Grasp and Babinski responses were found only in three dementia patients who had imaging signs of mild cortico-subcortical atrophy and diffuse or bilateral parietal-temporal hypoperfusion (see Table 2). One or more PR were elicited in $75 \%$ of controls, but none of these subjects had more than three such reflexes $(40.5 \%$ had only one; $26 \%$ had two; and $8.5 \%$ had three). More than three PR were found in 7 $(23.3 \%)$ dementia patients (even in three cases with mild dementia).

In the whole sample of demented and control subjects, frequency of PR tended to increase with the degree of cognitive deterioration $\left(\beta^{2}=28.8\right.$, 
Table 2. Demographics, dementia severity, total scores of primitive reflexes (PR), CASI-S and CAMCOG-S (Short Form), and results of SPECT [Holman's patterns] in the group of patients with Alzheimer's disease.

\begin{tabular}{|c|c|c|c|c|c|c|c|}
\hline Patient $\mathrm{nr}$ & Age/Sex & Education & DM severity & PR & CASI-S & CAMCOG-S & SPECT \\
\hline 1 & $76, F$ & 3 & Mild & 2 & 17 & 40 & [D] \\
\hline 2 & $73, F$ & 0 & Moderate & 3 & 28 & 35 & {$[\mathrm{H}]$} \\
\hline 3 & $72, F$ & 4 & Mild & 2 & 31 & 54 & [B] \\
\hline 4 & $89, M$ & 11 & Mild & 5 & 12 & 35 & {$[\mathrm{H}]$} \\
\hline 5 & $73, F$ & 4 & Mild & 0 & 23 & 42 & {$[\mathrm{~B}]$} \\
\hline 6 & $70, F$ & 11 & Moderate & 3 & 18 & 26 & [B] \\
\hline 7 & $53, F$ & 4 & Moderate & 4 & 6 & 17 & {$[E]$} \\
\hline 8 & $73, \mathrm{M}$ & 8 & Severe & 4 & 3 & 9 & {$[B]$} \\
\hline 9 & $71, F$ & 4 & Moderate & 4 & 21 & 39 & {$[\mathrm{C}]$} \\
\hline 10 & $68, F$ & 4 & Mild & 2 & 20 & 28 & [D] \\
\hline 11 & $81, F$ & 11 & Mild & 3 & 12 & 38 & ND \\
\hline 12 & $84, \mathrm{M}$ & 17 & Severe & 4 & 4 & 7 & ND \\
\hline 13 & $84, F$ & 11 & Mild & 6 & 13 & 28 & {$[\mathrm{~B}]$} \\
\hline 14 & $59, \mathrm{~F}$ & 11 & Severe & 6 & 0 & 3 & {$[\mathrm{H}]$} \\
\hline 15 & $64, M$ & 4 & Mild & 4 & 19 & 38 & [D] \\
\hline 16 & $77, \mathrm{M}$ & 3 & Mild & 1 & 27 & 52 & {$[C]$} \\
\hline 17 & $79, \mathrm{M}$ & 4 & Severe & 4 & 1 & 3 & ND \\
\hline 18 & $70, \mathrm{~F}$ & 15 & Mild & 2 & 16 & 61 & [D] \\
\hline 19 & $67, \mathrm{M}$ & 15 & Mild & 2 & 28 & 64 & {$[E]$} \\
\hline 20 & $56, \mathrm{M}$ & 4 & Mild & 0 & 28 & 49 & {$[\mathrm{~B}]$} \\
\hline 21 & $79, \mathrm{~F}$ & 8 & Mild & 1 & 11 & 33 & [D] \\
\hline 22 & $78, F$ & 11 & Moderate & 3 & 9 & 17 & ND \\
\hline 23 & $72, \mathrm{M}$ & 3 & Moderate & 5 & 27 & 41 & {$[C]$} \\
\hline 24 & $57, \mathrm{~F}$ & 4 & Severe & 10 & 3 & 6 & {$[\mathrm{H}]$} \\
\hline 25 & $63, \mathrm{M}$ & 4 & Severe & 3 & 2 & 9 & {$[C]$} \\
\hline 26 & $53, \mathrm{M}$ & 4 & Severe & 5 & 8 & 15 & {$[E]$} \\
\hline 27 & $71, \mathrm{~F}$ & 2 & Severe & 3 & 1 & 4 & {$[\mathrm{~B}]$} \\
\hline 28 & $74, \mathrm{~F}$ & 4 & Mild & 3 & 29 & 51 & {$[C]$} \\
\hline 29 & $73, \mathrm{~F}$ & 5 & Mild & 4 & 29 & 60 & {$[C]$} \\
\hline 30 & $78, F$ & 4 & Mild & 3 & 19 & 39 & {$[\mathrm{~B}]$} \\
\hline
\end{tabular}

DM, dementia; PR, primitive reflex; ND, not done

$\mathrm{df}=6, \mathrm{p}=0.0001)$ as well as with aging, particularly after 70 years age $\left(\beta^{2}=18.6, d f=6, p=0.004\right.$; Figure). PR scores were higher among dementia patients, particularly as regards paratonia $(p=$ $0.00001)$ and snout $(p=0.00001$; Mann-Whitney $\mathrm{U}$ test). There was a negative correlation between total scores of most cognitive subtests and those of each PR, mainly of paratonia, grasp and Babinski responses (Pearson correlation coefficient; see Table 3). In a multiple regression analysis of the whole sample, taking CASI-S as dependent variable and age, sex, and total scores of PR as independent variables, only age ( $\beta$ coefficient $=-.19$ ) and, particularly, PR total scores $(\beta=-.43)$ were significantly correlated to CASI-S scores.

In the dementia group, PR total scores were negatively correlated to CASI-S ( $\beta=-.47, p=0.008)$ and to CAMCOG-S total scores $(\beta=-.51, p=0.004)$. In this group, CASI-S total scores were highly correlated to those of CAMCOG-S $(\beta=.89, \mathrm{p}<0.001)$. 
Table 3. Correlations ( $r$ and $p$ values) between scores of primitive reflexes and cognitive tests in the whole sample of 184 subjects.

\begin{tabular}{lcccccccc}
\hline Variables & Palmomental & Glabellar & Snout & Suck & Grasp & Paratonia & $\begin{array}{c}\text { Babinski } \\
\text { sign }\end{array}$ & $\begin{array}{c}\text { Reflexes } \\
\text { total score }\end{array}$ \\
\hline Registration & NS & NS & NS & NS & $-0.29 * * *$ & $-0.31 * * *$ & $-0.31 * * *$ & $-0.30 * *$ \\
Orientation & $-0.25 * * *$ & NS & $-0.21 * *$ & $-0.14 *$ & $-0.35 * * *$ & $-0.44 * * *$ & $-0.21 * *$ & $-0.38 * * *$ \\
Verbal fluency & $-0.17 * *$ & NS & $-0.16 *$ & NS & $-0.29 * * *$ & $-0.31 * * *$ & $-0.14 *$ & $-0.30 * * *$ \\
Recall & NS & $-0.19 * *$ & $-0.17 *$ & $-0.21 * *$ & $-0.26 * * *$ & $-0.33 * * *$ & NS & $-0.36 * * *$ \\
Drawing & NS & NS & NS & $-0.16 *$ & $-0.19 * *$ & $-0.30 * * *$ & $-0.16 *$ & $-0.16 *$ \\
CASI-S total & $-0.21 * *$ & $-0.16 *$ & $-0.21 * *$ & $-0.17 *$ & $-0.35 * * *$ & $-0.42 * * *$ & $-0.18 *$ & $-0.40 * * *$ \\
\hline NS not significnt** & & & & & & & &
\end{tabular}

NS, not significant; * $<0.05 ;{ }^{* *}<0.01 ; * * *<0.001$.

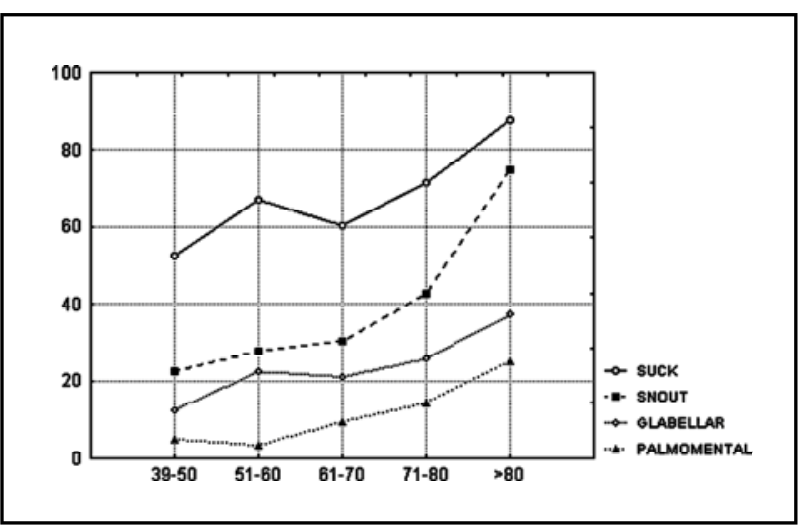

Figure Percentage of subjects in the whole sample of 184 sub jects with primitive reflexes (ordinate) distributed by age group (abscissa).

\section{DISCUSSION}

Paratonia, palmomental, glabellar, snout and suck reflexes were present in $5 \%$ to $62 \%$ of our no rmal controls, what indicates they are normal phenomenon found in the healthy population. Grasp and Babinski responses were detected only in patients with dementia, which confirms their pathological significance, as established in the literature None of control subjects, even among the oldest ones, had more than three PR. The presence of four or more PR, particularly the combination of paratonia, snout, suck and palmomental reflexes, especially if marked, were associated to cognitive deficit and diffuse or multiple brain dysfunction. This finding concur with those of other authors who called attention for the abnormal nature of multiple (more than three) PR, which in combination may be most predictive of organic pathology $^{3,23-25}$. Analysis of associations of PR with each other revealed correlations only between snout and glabellar reflexes, as also reported by some researchers ${ }^{26}$, without clear explanation; and between snout and suck reflexes, probably because these reflexes share overlapped neural structures.

Our data show that PR become more frequent and marked with aging, particularly after 70 years age, as well as with cognitive deterioration. A plausible explanation for reappearance of these reflexes in the adult has been the loss of cortical inhibition, resulting from atrophy of normal aging or more severe lesions of degenerative dementias ${ }^{1-8,25}$. The term "frontal release signs" for PR seems to be inappropriate, since almost all patients presenting them had atrophy and hypoperfusion predominantly in posterior regions, and other authors ${ }^{27}$ could not elicit any of them in a population of patients with frontal lobotomies.

In this study of associations between PR and cognitive performance, CASI-S showed to be a practical test, easy and quick to administer, suitable for illiterate subjects (that constitute $15 \%$ of our population of patients). It also has a high specificity, particularly among individuals from 70 years age, as shown in another study ${ }^{17}$. In the whole sample of demented and controls there was a negative correlation between total scores of PR and of CASI-S subtests. Our findings concur with those of the literature as regards the most predictive subtests found in other test batteries ${ }^{14,15}$, even in CASI complete form ${ }^{28}$ (temporal orientation, recall, verbal fluency, and constructional praxis), as well as the PR best correlated to brain lesion (paratonia, grasp and Babinski responses).

In the dementia group, the highest PR scores tended to associate to the lowest cognitive scores and to SPECT pattern $\mathrm{H}$. Thus, both the presence of multiple PRs and their scores could be useful $p$ redictors of diffuse cerebral dysfunction, as proposed by other authors ${ }^{2,25}$. 
In conclusion, the presence of grasp and $\mathrm{Ba}$ binski responses, or the combination of paratonia, snout, suck, and palmomental reflexes are strong indicators of diffuse brain dysfunction, especially when these signs are marked and accompanied by deficits in one or more of the cognitive subtests above mentioned. We think the standardized examination and graded scoring of these reflexes and cognitive functions should be included in the neurological bedside screening of patients with suspect degenerative dementia.

\section{REFERENCES}

1. Paulson G, Gottlieb G. Development reflexes: the reappearance of foetal and neonatal reflexes in aged patients. Brain 1968;91:37-52.

2. Jenkyn LR, Walsh DB, Culver CM, et al. Clinical signs in diffuse cerebral dysfunction. J Neurol Neurosurg Psychiatry 1977;41:956-966.

3. Jenkyn LR, Reeves AG, Warren T, et al. Neurologic signs in senescence. Arch Neurol 1985;42:1154-1157.

4. Huff FJ, Growdon JH. Neurological abnormalities associated with severity of dementia in Alzheimer's disease. Can J Neurol Sci 1986;13(Suppl) 4:S403-S405.

5. Bakchine S, Lacomblez L, Palisson E, et al. Relationship between primitive reflexes, extra-pyramidal signs, reflective apraxia and severity of cognitive impairment in dementia of the Alzheimer type. Acta Neurol Scand 1989;79:38-46.

6. Burns A, Jacoby R, Levy R. Neurological signs in Alzheimer's disease. Age Ageing 1991;20:45-51.

7. Vreeling FW, Jolles J, Ve rhey FR, et al. Primitive reflexes in healthy, adult volunteer sand neurological patients: methodological issues. J Neurol 1993; 240:495-504.

8. Hogan DB, Ebly EM. Primitive reflexes and dementia: results from the Canadian Study of Health and Aging. Age Ageing 1995;24:375-381.

9. Olney RK. The neurology of aging. In: AminoffMJ (ed), Neurology and general medicine. New York: Churchill Livingstone, 1994:947-962.

10. Adams RD, Victor M, Ropper AH. The neurology of aging. In: Adams RD, Victor M, Ropper AH (eds), Principles of neurology, $6^{\text {th }}$ edn. New York: McGraw-Hill., 1997:608-620.

11. Ansink JJ. Physiologic and clinical investigation into four brainstem reflexes. Neurology 1962;12:320-328.
12. Koller WC, Glatt S, Wilson RS, et al. Primitive reflexes and cognitive function in the elderly. Ann Neurol 1982;12:302-304.

13. Teng EL, Hasegawa K, Homma A, et al. The Cognitive Abilities Screening Instrument (CASI): a practical test for cross-cultural epidemiological studies of dementia. Int Psychogeriatr 1994;6:45-58.

14. Magaziner J, Basset SS, Hebel JR. Predicting performance on the MiniMental State Examination. J Am Geriatr Soc 1987;35:996-1000.

15. Teng EL, Riesenberg LA, Hall NK, et al. Comparisons among three screening tests for dementia. Presentation at the 1997 Annual Psychological Association, Chicago, IL.

16. Ng RTY, Damasceno A, Delicio AM, et al. Validation of mini-test CASI$\mathrm{S}$ in a sample of Brazilian population. J Int Neuropsychol Soc 2001;7:420 (Abstract).

17. Damasceno A, Delicio AM, Mazo DFC, Zullo JFD, Scherer P, Ng RTY, Damasceno BP. Validation of the Brazilian version of mini-test CASIS. Arq Neuropsiquiatr (submitted).

18. American Psychiatric Association. Diagnostic and Statistical Manual of Mental Disorders ( $4^{\text {th }}$ ed). Washington: APA, 1994.

19. McKahnn G, Drachman D, Folstein M, et al. Clinical diagnosis of Alzheimer's disease: report of the NINCDS-ADRDA Work Group under the auspices of Department of Health and Human Services Task Force on Alzheimer's disease. Neurology 1984;34:939-944.

20. Roth M, Huppert FH, Tym E, et al. CAMDEX: The Cambridge Examination for Mental Disorders of the Elderly. Cambridge: Cambridge University Press, 1988.

21. Nitrini R. Diagnóstico de demência: avaliação clínica, neuropsicológica e através da tomografia computadorizada por emissão de fóton único. Post-doctoral thesis, Faculdade de Medicina, Universidade de São Paulo, 1993.

22. Holman BL, Johnson KA, Gerada B, et al. The scintigraphic appearance of Alzheimer's disease: a prospective study using technetium99m-HMPAO SPECT. J Nucl Med 1992;33:181-185.

23. B rown DL, Smith TL, Knepper LE. Evaluation of five primitive reflexes in 240 young adults. Neurology 1998;51:322.

24. Isakov $\mathrm{E}$, Sazbon $\mathrm{L}$, Costeff $\mathrm{H}$, et al. The diagnostic value of three common primitive reflexes. Eur Neurol 1984;23:17-21.

25. Schott JM, Rossor MN. The grasp and other primitive reflexes. J Neurol Neurosurg Psychiatry 2003;74:558-560.

26. Tweedy J, Reding M, Garcia C, et al. Significance of cortical disinhibition signs. Neurology 1982;32:169-173.

27. Benson DF, Stuss DT. Motor abilities after frontal leukotomy. Neurology 1982; 32:1353-1357.

28. Tsai RC, Lin KN, Wu KY, Liu HC. Improving the screening power of the Cognitive Abilities Screening Instrument, Chinese version. Dement Geriatr Cogn Disord 2004;18:314-320. 